\title{
Research on automatic high velocity arc spraying technique and metastable coating materials
}

\author{
Xiu-Bing Liang • Yong-Xiong Chen • \\ Zhi-Bin Zhang $\cdot$ Shi-Cheng Wei $\cdot$ Yong-Ming Guo • \\ Bin-Shi Xu
}

Received: 20 September 2012/ Accepted: 4 November 2012/Published online: 13 March 2013

(C) Shanghai University and Springer-Verlag Berlin Heidelberg 2013

\begin{abstract}
Into the 21st century, remanufacturing engineering has been accepted by more and more people in China. Remanufacturing is an industrial maintenance technology for worn or waste electro-mechanical products using advanced technology, which means the high-level stage for the maintenance and surface engineering. In this paper, a new automotive high velocity arc spraying system was introduced. And three kinds of advanced amorphous and nanocrystalline metastable coatings were developed, including $\mathrm{Fe}, \mathrm{Ni}$ and $\mathrm{Al}$-based amorphous and nanocrystalline composite coatings. Their research development and applications were introduced. And the development trends of high velocity arc spraying system and advanced metastable surface protective coating materials on the remanufacturing engineering were indicated.
\end{abstract}

Keywords Remanufacturing · Arc spraying · Amorphous · Nanocrystalline $\cdot$ Coating

X.-B. Liang $(\bowtie) \cdot$ Y.-X. Chen

National Engineering Research Center for Mechanical Product

Remanufacturing, The Academy of Armored Forces

Engineering, Beijing 100072, People's Republic of China

e-mail: liangxiubing@yahoo.com.cn

Z.-B. Zhang · S.-C. Wei · Y.-M. Guo - B.-S. Xu

National Key Laboratory for Remanufacturing, The Academy

of Armored Forces Engineering, Beijing 100072,

People's Republic of China

Z.-B. Zhang

College of Materials Science and Engineering,

Beijing University of Technology, Beijing 100124,

People's Republic of China

\section{Introduction}

Remanufacturing is an industrialized process of recovering and upgrading worn or waste electromechanical products. It is based on the guidance of the entire life cycle design and management for electro-mechanical products, the goal of the performance leaps and bounds of waste electro-mechanical products, and the criterion of high-quality, high-efficiency, energy-saving, material-saving and environmental protection. Remanufacturing needs to use advanced technologies and industrialization for carrying out recovery and upgrading worn out or waste electro-mechanical products. The advanced technologies include modern surface technologies, advanced processing technologies and advanced detection techniques. That is one of the reasons why the remanufacturing engineering is different from repairing. In addition, it is the main point that the performance and quality of the remanufactured electro-mechanical products can reach or surpass those of the new products [1,2].

The high velocity arc spraying device and advanced spraying materials were developed by the authors in recent years. In this paper, a new automatic high velocity arc spraying system was introduced. And three kinds of high performance amorphous and nanocrystalline metastable composite coatings were also presented.

\section{Development of an automatic high velocity arc spraying system}

The automatic high velocity arc spraying technique is one of the important advanced remanufacturing technologies. Low running costs and high spraying efficiency make it a good process for large area spraying, so it has a wide application in industry [3,4]. As is well known, the arc 
spraying technology has already existed for about 100 years in the human history. With the advancement of science and technology, it has also been a considerable improvement. Especially the emergence of cored wire technique gives it a new chance. The cored wire technique overcomes the difficulty of high alloy composition material in wire-drawing, and gives some of the particulate materials a chance to be applied on the arc spraying technique. Moreover, the arc spraying equipment has been developed toward sophisticated and automated direction in recent years, which further improved the coating's quality and increasingly widespread the range of the application of the arc spraying technique.

A new automatic high velocity arc spraying system was developed at the National Key Laboratory for Remanufacturing. A prosthetic robot is one of the primary choices for the automatic high velocity arc spraying system owing to its big operating space and operating speed range, flexible operating posture control, and mature technology. According to the industrial applied demands, the automatic high velocity arc spraying system designed consists of high performance arc spraying equipments, an MOTOMAN HP20 robot control system and procedure quality monitoring equipments, and so on [3,4]. Figure 1 shows the entire structure diagrammatic sketch of the automatic high velocity arc spraying system. Figure 2 shows the main

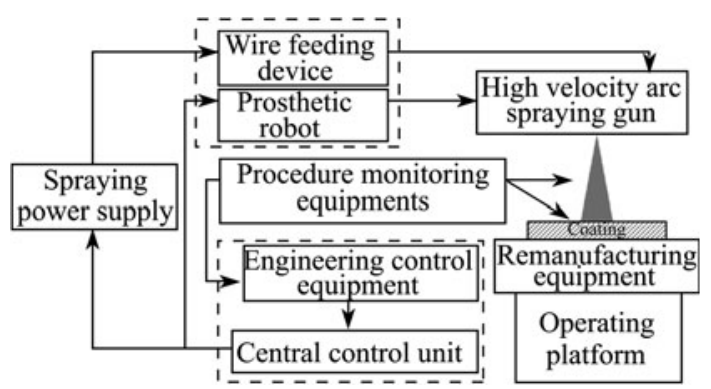

Fig. 1 Entire structure diagrammatic sketch of the automatic high velocity arc spraying system

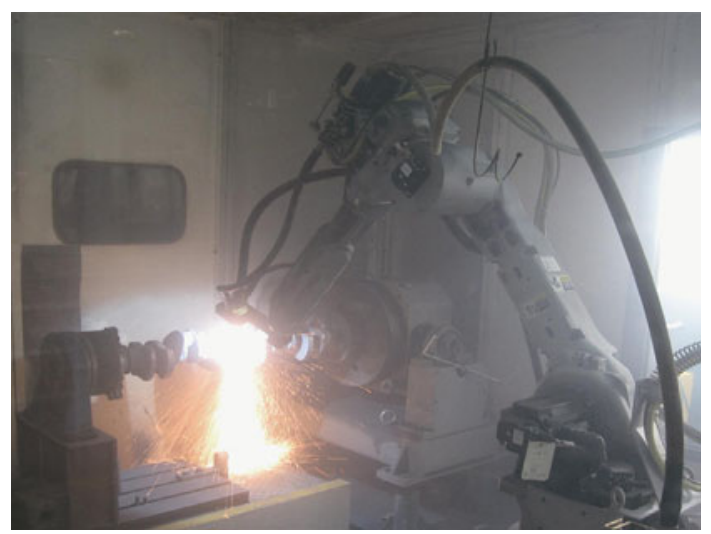

Fig. 2 Image of the automatic high velocity arc spraying system body of the newly designed automatic high velocity arc spraying system. A high velocity arc spraying gun is clamped with a special purpose holding device that is fixed at the end of the robot arm. In order to ensure reliable work, the wire feeder is fixed at the affix arm of the robot. The wire feeding distance is cut down at the range of $0.9-1.2 \mathrm{~m}$ so as to reduce the wire feeding drag force and avoid the interference with spraying device and robot. The remanufacturing component is fixed on the operating platform. All the control operations of the automatic spraying procedure are carried out using the integrated central control unit. In addition, the central control unit is equipped with the real-time feedback controls digital interface, hence the procedure quality monitoring equipments can be applied to monitor the flying state of the spraying droplet and the temperature field of the coating surface.

The design above all can carry out the optimum control of the automatic system to ensure the stability of the sprayed coating quality.

A digital inverter arc spraying power supply can supply rated current output of $500 \mathrm{~A}$ (maximum peak current of $700 \mathrm{~A}$ ) and no-load voltage of $70 \mathrm{~V}$. According to the principle of aerodynamics, the high velocity arc spraying gun was developed which made the atomization airflow velocity higher than $500 \mathrm{~m} / \mathrm{s}$. And the spraying velocity of iron-based material was increased from 100 to $150 \mathrm{~m} / \mathrm{s}$, which can significantly promote the coating performance and deposition efficiency. Thus, the system gives the arc spraying technique a promotion from traditional extensive form to advanced and high-efficiency maintenance technology with spraying process and coating quality precisely controlled.

The high velocity arc spraying system has been used by the Jinan Fuqiang Power Co., Ltd. to manufacture the automobile engine block and crankcase and other typical parts [5]. It saves a great deal of rough stocks and energy, enhances the performance of the parts, decreases the cost, and improves the efficiency. In addition, it will take about 20 min to remanufacture a crankshaft. As compared with traditional technique, it saves about $1.2 \mathrm{~h}$. Thus the system provides a great deal of social and economical benefits.

\section{Research on advanced metastable alloy coating materials}

In the 21 st century, amorphous and nanocrystalline metastable materials have been of interest not only for fundamental studies, but also for potential applications [6]. High velocity arc spraying technique is one of the surface amorphization technologies because of its sufficiently rapid cooling rate of $10^{5} \mathrm{~K} / \mathrm{s}$, which can be sufficient to create 
amorphous or nanostructured deposits [7]. In addition, it has advantages with high coating deposition efficiency and low cost which is suitable for the preparation of large area amorphous and nanocrystalline composite surface coating.

\subsection{Fe-based amorphous and nanocrystalline composite coating}

The arc sprayed Fe-based amorphous and nanocrystalline composite coating has a strong potential for industrial application owing to its excellent wear loss, anti-corrosion and easy forming. Compared to the conventional Fe-based alloy materials, the Fe-based amorphous and nanocrystalline composite coating has high strength, high hardness, low porosity, low oxide content, high deposition efficiency, high wear and corrosion resistance, etc., that can be used in the automotive, aerospace and other industrial sectors. This type of amorphous and nanocrystalline composite coating materials developed quickly become an international thermal spray material research focus. The author is one of the researchers that use high velocity arc spraying technique to prepare Fe-based amorphous and nanocrystalline composite coating.

The FeBSiNb [8] type of amorphous and nanocrystalline composite coating is one of the research results of the author research group. Figure 3 shows the test results of the $\mathrm{FeBSiNb}$ amorphous and nanocrystalline composite coating. It can be obtained from Fig. 3a that the FeBSiNb coating has a high amorphous content of about $80 \%$. Both of the porosity and oxide content are less than $1 \%$, as shown in Fig. 3b. The microhardness of the coating is at the range of 1,050-1,150 $\mathrm{HV}_{0.1}$, and the average bonding strength is up to $58 \mathrm{MPa}$. Figure $3 \mathrm{c}$ shows the wear loss distribution of $\mathrm{FeBSiNb}$ amorphous coating, 3Cr13 steel coating and 45\# steel substrate under the condition of the normal loads of 100 and $500 \mathrm{~N}$, linear speed of $0.84 \mathrm{~m} / \mathrm{s}$, and dry friction. The results present that relative abrasion resistance of the FeBSiNb coating is 5-6 times higher than that of $3 \mathrm{Cr} 13$ steel coating and 10 times higher than that of 45\# steel. The FeBSiNb coating presents an excellent abrasion resistance. This coating material has been applied by the Jinan Fuqiang Power Co., Ltd. to remanufacture the crankshaft.

\subsection{Ni-based amorphous and nanocrystalline composite coating}

The Ni-based amorphous and nanocrystalline wear-resistant coating is also one of the research results of the author. The coating can not only make sure the wear-resistant and friction-reducing effect of the crankshaft surface in the normal working status, but also play an important role in
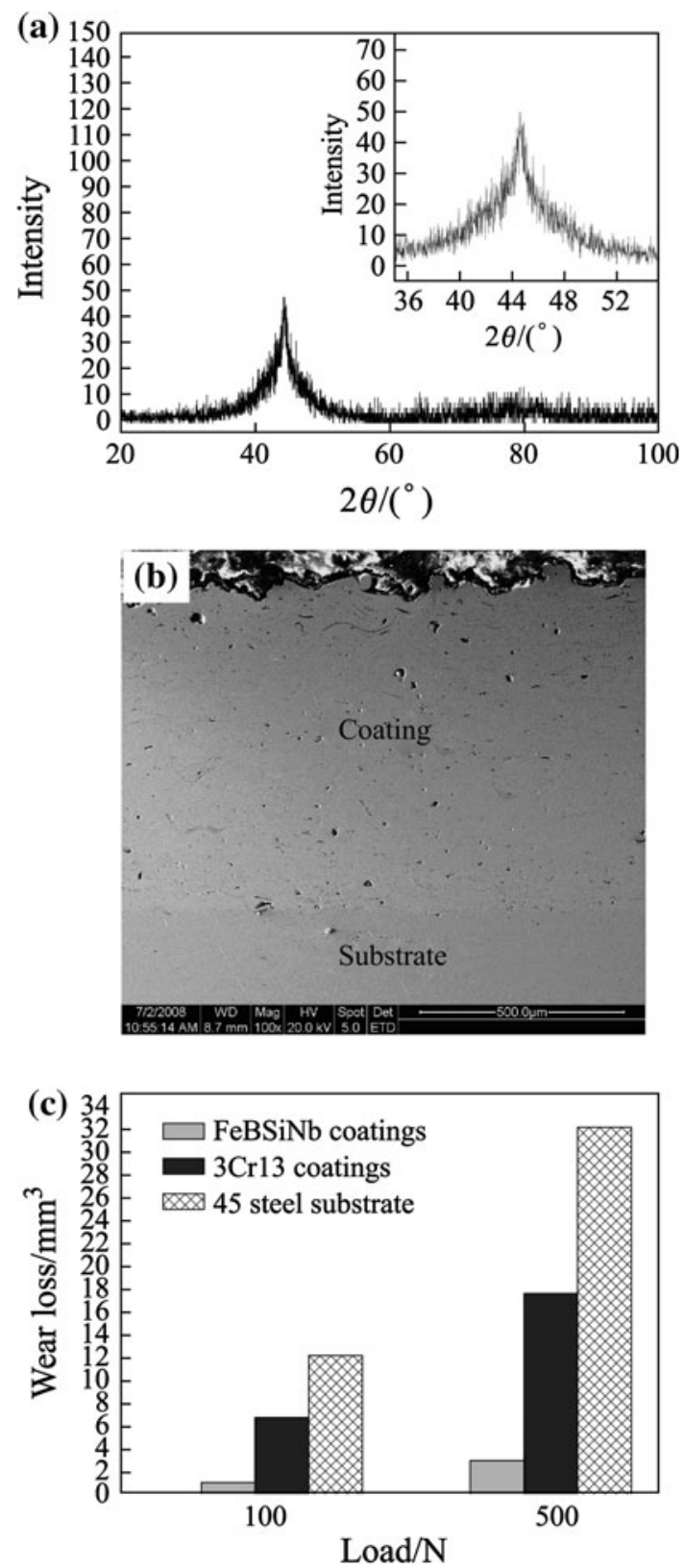

Fig. 3 Test results of FeBSiNb amorphous and nanocrystalline composite coating a XRD pattern, b SEM image of cross-section and $\mathbf{c}$ wear loss with different loads of 100 and $500 \mathrm{~N}$

protecting the friction pair to extend the service life of the crankshaft. The research on using automotive high velocity arc spraying technology to prepare Ni-based amorphous and nanocrystalline wear-resistant coating has rarely been reported.

The NiCrBMoFe amorphous and nanocrystalline composite coating was developed. Figure 4 shows the test result of the $\mathrm{NiCrBMoFe}$ coating. It consists of amorphous and nanocrystalline phases, as shown in Fig. 4a. The amorphous content in the coating is around $25 \%-45 \%$. The coating has a compact structure with a low porosity of 
about $2.0 \%$, as shown in Fig. 4b. The average coating bonding strength with the steel is about $48 \mathrm{MPa}$. The mean microhardness value of the coating is $500 \mathrm{HV}_{0.1}$. The wear resistance test results show that the coating has an excellent wear resistance as 8 times that of the $45 \#$ steel substrate material, as shown in Fig. 4c. This composite coating can be used to remanufacture the high-load axis.

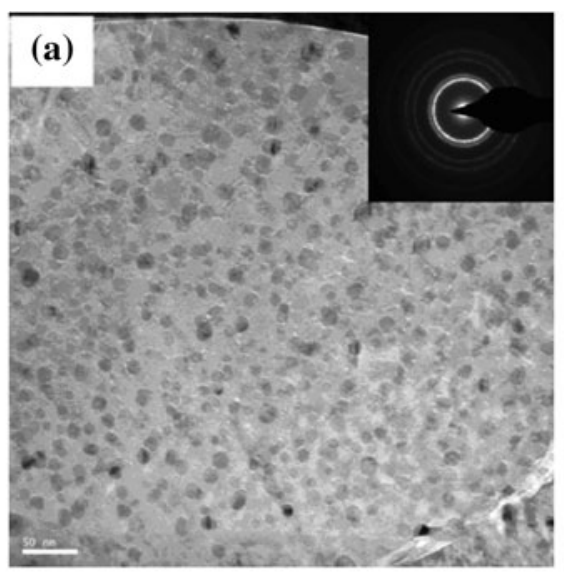

\section{(b)}
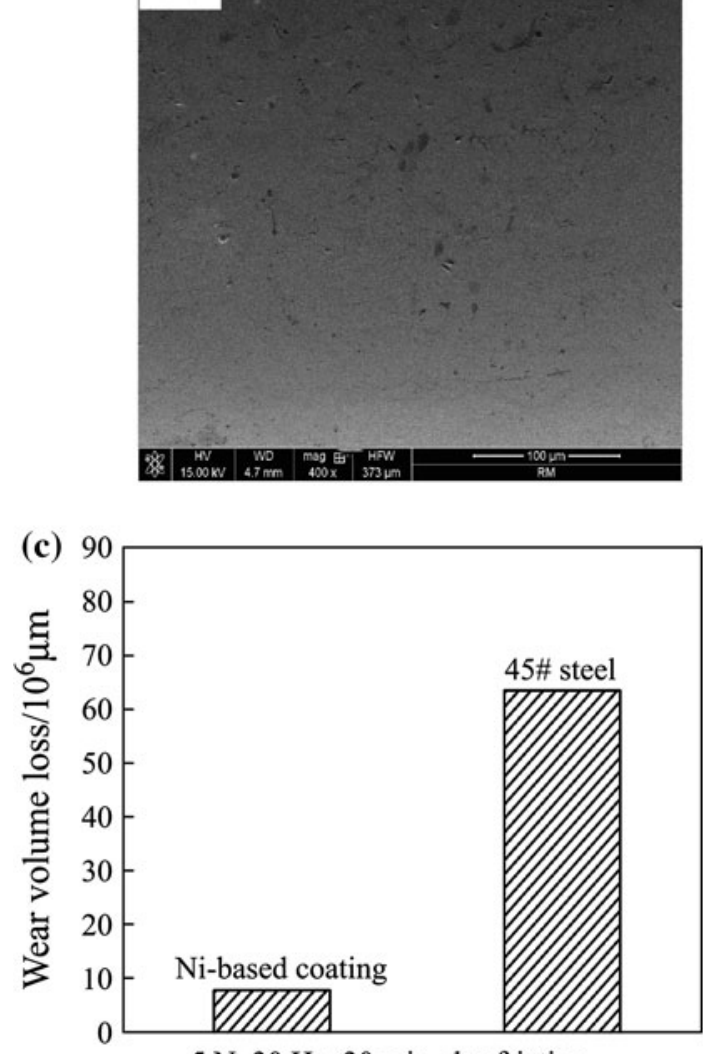

$5 \mathrm{~N}, 30 \mathrm{~Hz}, 30 \mathrm{~min}$, dry friction

Fig. $4 \mathrm{NiCrBMoFe}$ amorphous and nanocrystalline wear-resistant coating a TEM image, b SEM image of cross-section, $\mathbf{c}$ wear volume loss

\subsection{Al-based amorphous and nanocrystalline composite coating}

As compared with the Al-based traditional alloy materials, Al-based amorphous and nanocrystalline composite coating has higher hardness, higher corrosion resistance, higher wear resistance, etc. However, publications about using arc spraying technique to prepare Al-based amorphous and nanocrystalline composite coating were rarely reported. Based on the composition design rule of the Al-based amorphous bulk alloy materials, Al-Ni-Y-Co amorphous and composite coating was deposited and researched [9].
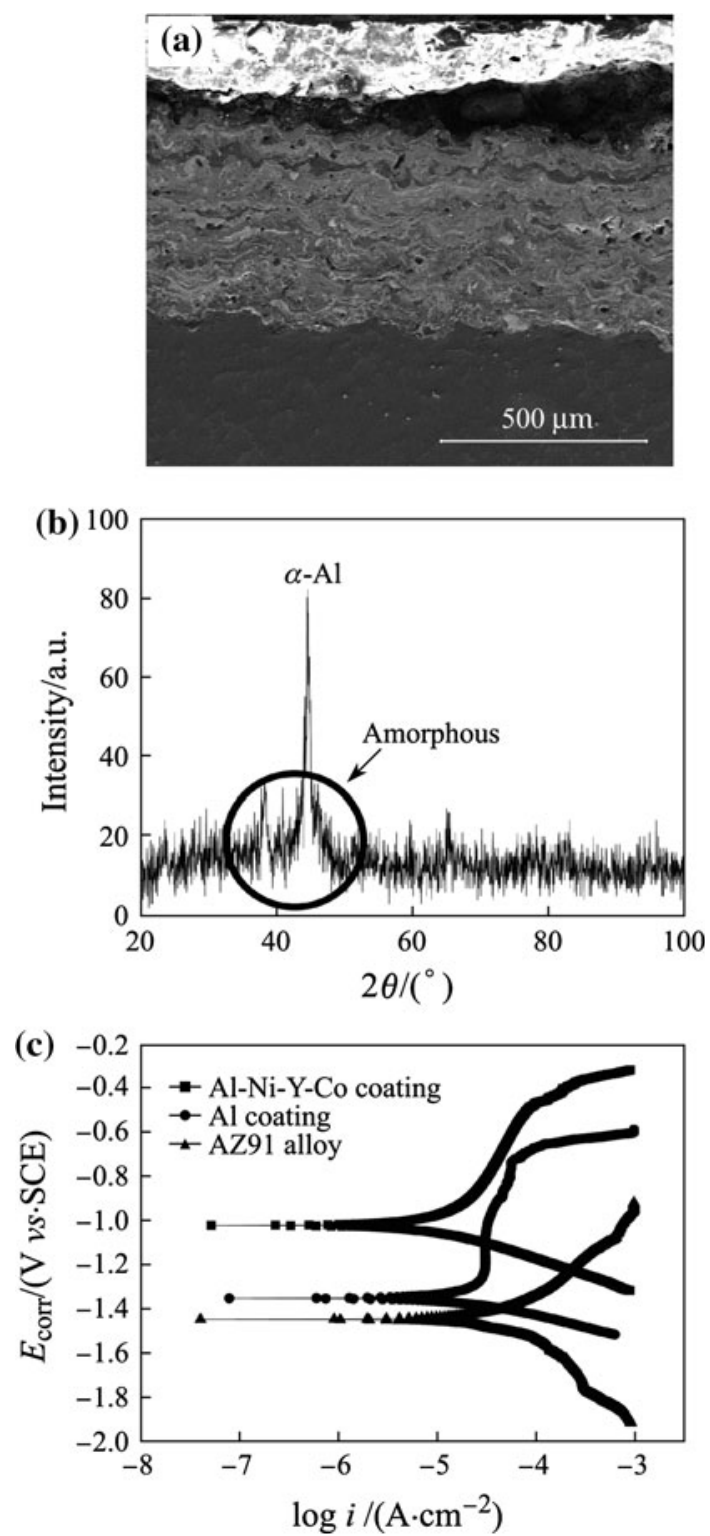

Fig. 5 Test results of Al-Ni-Y-Co amorphous and nanocrystalline coating a SEM image of cross section, b XRD pattern and c electrochemical polarization curves 
Figure 5 shows the characterization images of Al-Ni-Y-Co amorphous and nanocrystalline coating. It has a compact structure with low porosity about $1.8 \%$, as shown in Fig. 5a. It can be found from Fig. 5b that the coating composes of amorphous, nanocrystalline and microcrystalline phases. The average microhardness and bond strength of this coating are about $311 \mathrm{HV}_{0.1}$ and $26.8 \mathrm{MPa}$, respectively. Its relative wear resistance is about 10 times that of conventional arc-sprayed pure $\mathrm{Al}$ coating. And the coating has excellent corrosion resistance, as shown in Fig. 5c, which shows the polarization curve of the Al-Ni-Y-Co coating, traditional surface protective Al-coating for steel and common AZ91 magnesium alloy immersed after $0.5 \mathrm{~h}$ in $5 \mathrm{wt} \% \mathrm{NaCl}$ solution. The corrosion potential of the samples decreases in the order of Al-Ni-Y-Co coating (about $-1.004 \mathrm{~V}$ ) $>\mathrm{Al}$ coating (about $-1.335 \mathrm{~V})>\mathrm{AZ} 91$ alloy (about $-1.431 \mathrm{~V}$ ). The corrosion current of the samples increases in the order of Al-Ni-Y-Co coating $\left(11.11 \mu \mathrm{A} / \mathrm{cm}^{2}\right)<\mathrm{Al}$ coating $\left(30.31 \mu \mathrm{A} / \mathrm{cm}^{2}\right)<\mathrm{AZ} 91$ alloy $\left(54.17 \mu \mathrm{A} / \mathrm{cm}^{2}\right)$. And the polarization resistance $\left(R_{\mathrm{p}}\right)$ of the samples decreases in the order of Al-Ni-Y-Co coating $(3.726 \mathrm{k} \Omega)>\mathrm{Al}$ coating $(1.430 \mathrm{k} \Omega)>\mathrm{AZ} 91$ alloy $(0.970 \mathrm{k} \Omega)$.

So it indicates that the Al-Ni-Y-Co amorphous and nanocrystalline composite coating exhibits an excellent corrosion resistance that can be applied to protect the steel and light alloys and likely would become the next generation of surface protective coating material for steel structure of equipment.

\section{Conclusions}

The research history on using high velocity arc spraying technique to prepare metastable coating is short, and the improving room of the quality and performances of the coating is very big, thus it provides an opportunity for the researchers to carry out research and promote the application. The automotive high velocity arc spraying system was developed, that made sure the stability of the coating's quality and performance, carried out the repeatability of the spraying process and quality, and enhanced the technical level of remanufacturing. The research on advanced metastable coating needs to be deeply developed, for example, the content of amorphous or nanocrystalline phases needs precise control, the study on the basic mechanism of the metastable coating needs to be further performed, etc. Thus, to improve automotive high velocity arc spraying system, and to systematically develop and research metastable coating materials, they are the research focal points in future. In addition, to focus on the combination of production, studying and researching, the latest research achievements needs to be transformed into the productivity to contribute for remanufacturing industry.

\section{References}

1. Xu BS, Liu SC, Zhu ZX (2005) Foundations and applications of remanufacturing engineering. Harbin Institute of Technology Press, Haerbin

2. Chen YX, Xu BS, Xu Y et al (2006) Progress in applying HVAS technology to maintenance and remanufacturing engineering. China Surf Eng 19(S1):169-173

3. Liang XB, Chen YX, Bai JY et al (2010) An automatic high velocity arc spraying technology applied to remanufacture engine crankshaft. China Surf Eng 23(2):112-116

4. Liang XB, Xu BS, Ma SN (2002) Measurement and analyses of high velocity arc spraying technique characteristics. Chin J Mech Eng 38(2):57-60

5. Xu BS (2008) The remanufacturing engineering and automatic surface engineering technology. Key Eng Mater 373(374):1-10

6. Liang XB, Xu BS, Wei SC et al (2009) Research progress in thermal spraying metastable composite coating. Mater Rev 5:1-4

7. Cheng JB, Liang XB, Xu BS et al (2009) Characterization of mechanical properties of FeCrBSiMnNbY metallic glass coatings. J Mater Sci 44(13):3353-3363

8. Liang XB, Cheng JB, Bai JY et al (2009) Microstructure and erosion properties of $\mathrm{Fe}$-based amorphous and nanocrystalline coatings. Trans China Weld Inst 30(2):61-64

9. Liang XB, Zhang ZB, Chen YX et al (2012) Study on Al-based amorphous and nanocrystalline composite coating. Acta Metall Sinca 48(3):289-297 